\title{
Port catheters: Indications, complications and quality of life
}

\author{
Ummugul Uyeturk
}

Department of Medical Oncology, Ceylan International Hospital, Bursa, Turkey

\section{ABSTRACT}

Port catheters are very critical component in the care of patients with chronic diseases such as cancer that require frequent hospitalization and venous access. Because port catheters can be used for biochemical analysis of blood, administration of chemotherapeutic agents, transfusion of blood and blood products, fluid and antibiotic support, and total parenteral nutrition. Port catheters can be placed safely and easily under ultrasound guidance. Port catheters, whose early or late complications are rarely seen, provide a significant improvement in the quality of life of patients compared to other venous access catheters.

Key words: Antineoplastic agents, catheterization, ports catheters, adverse effects, quality of life.

Ummugul Uyeturk, M.D., Associate. Prof. Department of Medical Oncology, Ceylan International Hospital, Bursa, Turkey

E-mail: ummuguluyeturk@yahoo.com.tr

Received: 2021-09-19/

Accepted: 2021-10-18/ Published online: 2021-11-01

\section{Introduction}

Intravenous access is often required for biochemical blood analysis and treatments of patients admitted to the hospital. This access is often via peripheral venous catheterization. However, central venous access is required in patients who need intensive treatment for central venous pressure monitoring, fluid replacement, long-term total parenteral nutrition, blood and blood product transfusion, drug administration (especially chemotherapeutic drugs). It is the procedure of placing a catheter in a vein that joins the heart directly [1].

The use of central venous catheters goes back to 1929 , when Werner Forssman used a plastic cannula from the peripheral arm vein to the heart [2]. Access to the subclavian vein was described in 1952 for central venous access [3].
Silicon-based catheters were started to be used by Broviac in 1973 and Hickman in 1977 [4]. Since 1982, implantable venous access systems have been used instead of peripheral venous vessels in situations requiring repetitive blood collection and regarded as a suitable method to administrate drugs used in cancer therapy [5].

\section{Central venous catheters}

Central venous access can be performed by a central venous catheter or peripherally inserted central catheter. There is no clear superiority of any procedure type, central venous catheter or peripherally inserted central catheter, for venous access [6].Nowadays non-tunneled central venous catheters, tunneled central venous catheters and subcutaneously implanted ports are used for central venous access [7].

\section{Non-tunneled central venous catheters}

It is used in patients whose condition is unstable, require hemodynamic monitoring, acute care, need high volume fluid replacement, multiple therapy, blood and blood product transfusion and parenteral nutrition, by 
providing access to the internal jugular vein and need treatment for 14 days or less [8]. Antimicrobial non-tunnelled catheters are often used for these critical patients to reduce the risk of infection by approximately $40 \%$ [9].

\section{Tunneled central venous catheters}

It is placed subcutaneously in the jugular or subclavian vein. These catheters are used for patients who need vesicant and irritant treatment for 31 days or longer, and are administered parenteral nutrition or chemotherapeutic agents. These catheters can be used especially if patients need to be hospitalized for longer than 15 days [10].

\section{Ports catheters}

Ports catheters provide a safe access route for administering blood collection, therapeutic purposes, including chemotherapy, parenteral nutrition, blood transfusions for biochemical analysis without impairing or minimally affecting patients' life quality [11]. Port catheters are often used for patients who require long-term central venous access. It is especially recommended if there is a need for intermittent or cyclic infusion treatment for 6 months or longer $[8,12]$.

\section{Who should place the port catheters?}

While port catheter placement was previously performed under general anesthesia, nowadays it is easily performed using ultrasonographic and fluoroscopy imaging methods by interventional radiology with intravenous sedation (midazolam/fentanyl) in a safe, effective and rapid way [13].

In one study, it was found that port catheters placed by general surgeons and interventional radiologists had similar complication rates. Nevertheless, when hospital costs were compared, it was determined that the cost of port catheter placed by interventional radiologist was lower. However, it has been concluded that placement of ports in a special reserved environment by general surgeons and/or interventional radiologists instead of academic centers can reduce costs by minimizing overheads [14].

\section{How is port catheter placement performed under ultrasound guidance?}

In clinical practice, while inserting an ultrasound-guided port catheter;

I-The anatomy of the insertion site and the localization of the vessel should be determined, II- It should be checked whether the vein is open,

III-Ultrasound should be used as a guide for venous puncture,

IV- The position of the needle in the vein should be checked,

V-Catheter position in vein should be checked [15-17].

What are the port catheter complications?

Port catheter complications can be evaluated as early if they occur within 30 days of implantation, and as late complications if they occur after 30 days. Early complications are intravenous or cardiac malposition, arrhythmias, hemothorax and cardiac tamponade as a result of perforation and bleeding, pneumothorax, ductus thoracic injury and air embolism. The universal use of ultrasound guidance for vein puncture has significantly reduced procedural and early complications [18]. Late complications include infections, venous thrombosis, pulmonary embolism, catheter breakage, migration and air embolism [19, 20].

Complications can be minor or major. Minor complications are those that do not require surgical or medical treatment within more than 
24 hours. Major complications are those that require surgical or medical intervention in less than 24 hours, require hospitalization, and can lead to consequences, even to death. Hemothorax and pneumothorax are the most common major complications [18, 19].

In a study, complications were found in 34 (4\%) patients out of 827 patients who underwent port catheterization between 2013 and 2015. As complications of chamber insertion, infection was seen in 5 patients $(0.6 \%)$ and erosion in 6 patients $(0.7 \%)$. The most common complication was catheter-related complications $(n=19,2.3 \%)$. It was found that catheter-related infection was seen in 7 patients $(0.8 \%)$, catheter migration in 8 patients $(1 \%)$, catheter-related thrombosis in 4 patients $(0.5 \%)$, and chamber malposition in 2 patients $(0.3 \%)$ [21].

In another study, in which 782 patients were evaluated between 2010 and 2018 to evaluate the early and late complications of port catheters, the most serious complication was pneumothorax in 7 patients and thrombotic occlusion of the catheter as a late complication. $2 / 3$ of patients with thrombosis-related obstruction required thrombolytic treatment [22].

In a study of 399 patients who underwent chemotherapy between 2013 and 2017, the complication rates of port catheters or peripheral inserted central catheters were evaluated (peripheral inserted central catheter $\mathrm{n}=201$ and port catheter $\mathrm{n}=198) .16(8 \%)$ deep venous thrombosis was found in the peripheral inserted central catheter group, while $2(1 \%)$ patients had port catheter group [23].

The patients were examined for port-related complications and thrombosis including port occlusion. Routinely, catheter care was done by using of heparin. In a study on this subject, there was no difference between the common and rare port care groups in terms of serious port-related complications during follow-up. However, the rate of thrombosis was found to be slightly higher in the rare port care group [24].

What is the effect of the port catheter on the patients' quality of life?

In a study evaluating the effects of peripheral venous catheters and central port catheters on the quality of life of patients with breast cancer and colon cancer; Complication rates of these two catheters were found to be similar. However, although port catheter procedures are slightly more painful than the other procedures, it has been found to have more positive results on quality of life when examined from a psychosocial perspective [25]. It has been found that port catheters have positive effects on the quality of life of patients with breast cancer, even if they are placed in different regions (chest, arm, trapezius muscle, etc.) in patients with breast cancer $[26,27]$.

\section{Conclusion}

These catheters, which can be placed safely and easily in patients with chronic diseases requiring recurrent venous intervention, have an important place in blood analysis and treatment without impairing the quality of life of the patients.

Funding: The author(s) received no financial support for the research, authorship, and/or publication of this article.

Conflict of Interest: The authors declare that they have no conflict of interest.

Ethical statement: Since this research is a review study, no ethics committee decision was required. 


\section{Open Access Statement}

This is an open access journal which means that all content is freely available without charge to the user or his/her institution under the terms of the Creative Commons Attribution NonCommercial License

(http://creativecommons.org/licenses/bync/4.0). Users are allowed to read, download, copy, distribute, print, search, or link to the full texts of the articles, without asking prior permission from the publisher or the author.

Copyright (c) 2021: Author (s).

\section{References}

[1] Lee KA, Ramaswamy RS. Intravascular access devices from an interventional radiology perspective: indications, implantation techniques, and optimizing patency. Transfusion. 2018;58 Suppl 1:54957.

[2] Forssmann W. Die Sondierung des Rechten Herzens. Klinische Wochenschrift. 1929;8:2085-87.

[3] Aubaniac R. Subclavian intravenous injection; advantages and technic. Press Med. 1952;60(68):1456.

[4] Heberlein W. Principles of tunneled cuffed catheter placement. Tech Vasc Interv Radiol. 2011;14(4):192-7.

[5] Niederhuber JE, Ensminger W, Gyves JW, et al. Totally implanted venous and arterial access system to replace external catheters in cancer treatment. Surgery. 1982;92(4):70612.

[6] Santos FKY, Flumignan RLG, Areias LL, et al. Peripherally inserted central catheter versus central venous catheter for intravenous access: A protocol for systematic review and meta-analysis. Medicine (Baltimore). 2020;99(30):e20352.

[7] Maria K, Theodoros K, Maria B, et al. Implementation of tunneled versus not tunneled peripherally inserted central catheters. J Vasc Nurs. 2019;37(2):132-134.

[8] Chopra V, Flanders SA, Saint S, et al. The Michigan Appropriateness Guide for Intravenous Catheters (MAGIC): Results From a Multispecialty Panel Using the RAND/UCLA Appropriateness Method. Ann Intern Med. 2015;163(6 Suppl):S1-40.

[9] Lorente L, Lecuona M, Jiménez A, et al. Efficiency of chlorhexidine-silver sulfadiazine-impregnated venous catheters at subclavian sites. Am J Infect Control. 2015;43(7):711-4.

[10] Tran H, Arellano M, Chamsuddin A, et al. Deep venous thromboses in patients with hematological malignancies after peripherally inserted central venous catheters. Leuk Lymphoma. 2010;51(8):1473-7.

[11]Dariushnia SR, Wallace MJ, Siddiqi NH, et al. Quality improvement guidelines for central venous access. J Vasc Interv Radiol. 20101;21(7):976-81.

[12] Simonova G, Rickard CM, Dunster KR, et al. Cyanoacrylate tissue adhesives - effective securement technique for intravascular catheters: in vitro testing of safety and feasibility. Anaesth Intensive Care. 2012 May;40(3):460-6.

[13] Ananthakrishnan G, McDonald R, Moss J, et al. Central venous access port devices - a pictorial review of common complications from the interventional radiology perspective. J Vasc Access. 2012;13(1):915.

[14]LaRoy JR, White SB, Jayakrishnan T, et al. Cost and Morbidity Analysis of Chest Port Insertion: Interventional Radiology Suite Versus Operating Room. J Am Coll Radiol. 2015;12(6):563-71.

[15] Saugel B, Scheeren TWL, Teboul JL. Ultrasound-guided central venous catheter 
placement: a structured review and recommendations for clinical practice. Crit Care. 2017;21(1):225.

[16] Gawda R, Czarnik T. A systematic approach to ultrasound-guided central venous catheter placement-desirable modifications. Crit Care. 2017;21(1):299.

[17] Gonda SJ, Li R. Principles of subcutaneous port placement. Tech Vasc Interv Radiol. 2011;14(4):198-203.

[18] Walser EM. Venous access ports: indications, implantation technique, followup, and complications. Cardiovasc Intervent Radiol. 2012;35(4):751-64.

[19] Machat S, Eisenhuber E, Pfarl G, et al. Complications of central venous port systems: a pictorial review. Insights Imaging. 2019;10(1):86.

[20]Pinelli F, Cecero E, Degl'Innocenti D, et al. Infection of totally implantable venous access devices: A review of the literature. J Vasc Access. 2018;19(3):230-242.

[21] Kim DH, Ryu DY, Jung HJ, et al. Evaluation of complications of totally implantable central venous port system insertion. Exp Ther Med. 2019;17(3):2013-2018.

[22][22] Ince ME, Ozkan G, Ors $\mathrm{N}$, et al. Complications and pitfalls of central venous port catheters: experience with 782 patients with cancer. Ir J Med Sci. 2020 ;189(4):13711377.

[23][23] Taxbro K, Hammarskjöld F, Thelin B, et al. Clinical impact of peripherally inserted central catheters vs implanted port catheters in patients with cancer: an open-label, randomised, two-centre trial. Br J Anaesth. 2019;122(6):734-741.

[24] Odabas H, Ozdemir NY, Ziraman I, et al. Effect of port-care frequency on venous port catheter-related complications in cancer patients. Int J Clin Oncol. 2014;19(4):761-6.
[25] Burbridge B, Lim H, Dwernychuk L, et al. Comparison of the Quality of Life of Patients with Breast or Colon Cancer with an Arm Vein Port (TIVAD) Versus a Peripherally Inserted Central Catheter (PICC). Curr Oncol. 2021;28(2):1495-1506.

[26]Liu Y, Xu L, Jiang M, et al. Chinesization of the quality of life assessment, venous deviceport, and its reliability and validity tests for patients with breast cancer. J Vasc Access. 2020;21(6):983-989.

[27]Çil BE, Öcal O, Eldem FG, et al. Trapezius Port Placement in Patients with Breast Cancer: Long-Term Follow-up and Qualityof-Life Assessment. J Vasc Interv Radiol. 2019;30(1):69-73. 